\title{
ESTUDIO GENERAL
}

\section{EVALUACIÓN DE LA CAMPAÑA DE VACUNACIÓN EN CANTABRIA DOS AÑOS DE EVOLUCIÓN EPIDEMIOLÓGICA}

\author{
Álvaro González de Aledo y Jesús García Merino \\ Coordinadores de la campaña de vacunación antimeningocócica en Cantabria.
}

\section{RESUMEN}

Se presentan los resultados de la campaña de vacunación antimeningocócica realizada en Cantabria en febreromarzo de 1997. A corto plazo, la campaña tuvo el efecto de disminuir la tasa de incidencia en el grupo de riesgo desde $21,33 / 100.000$ en los 12 meses previos, a cero en los 12 meses posteriores. A medio plazo ( 2 años y medio después), la incidencia se ha mantenido un $80 \%$ más baja en el grupo de riesgo y un $77,3 \%$ más baja en el conjunto de Ia población. La efectividad vacunal en el tercer año tras la campaña se mantiene por encima del $91 \%$ en todas las edades, aunque algunos sesgos comentados en el trabajo hacen que esta efectividad esté infraestimada. Por otra parte, la efectividad vacunal es muy superior a los porcentajes de seroprotección medidos por la tasa de anticuerpos bactericidas, especialmente en las edades menores. Los casos clínicos en vacunados han tenido un curso clínico benigno.

Palabras clave: Enfermedad menongocócica. Vacunación Evaluación.

\section{ABSTRACT \\ Evaluation of the Vaccination Campaign in Cantabria}

Two Years of Epidemiological Evolution

The results of the meningococcal vaccination campaign carried out in Cantabria in February-March 1997 are presented. In the short term, the campaign reduced the rate of incidence in the risk group from $21.33 / 100,000$ in the previous 12 months, to zero in the 12 months following the campaign. In the medium term ( 2 and a half years later), the rate of incidence was maintained $80 \%$ lower in the risk group and $77.3 \%$ lower in the population overall. The vaccinal efficacy in the third year following the campaign remained above $91 \%$ for all age groups, although some biases commented upon in the study have meant that this efficacy has been underestimated. Also, the vaccinal efficacy is much higher than the percentuges of seroprotection measured by the rate of bactericidal antibodies, particularly in the younger age groups. The clinical cases in vaccinated individuals experienced a benign clinical course.

Key words: Mcningococcal disease. Vaccination Evaluation.

\section{INTRODUCCIÓN}

En Febrero de 1997 se constató en Cantabria un brote epidémico de meningitis $\mathrm{C}$, con una tasa de incidencia (en los 12 meses inmediatamente anteriores) de $10,8 / 100.000$ en la población general y de 21,33/100.000 en el «grupo de riesgo» de 18 meses a 19 años, y una tasa primaria de ataque (en el grupo de riesgo) de 14/100.000 a finales del mes de febrero del 97. La letalidad era del $11,11 \%$ para el serogrupo $\mathrm{C}$.

La campaña de vacunación se comenzó a las 3 semanas de superarse la tasa primaria de ataque de 10/100.000, y en 2 semanas se con- siguió vacunar al 93,45\% de la población diana. Posteriormente, debido al escaso carácter estacional de la enfermedad en Cantabria, se mantuvo abierta la vacunación hasta abril de 1999 para todos los lactantes que fueran cumpliendo 18 meses. La cobertura final en los 26 meses que duró la vacunación fue del 98,75\%.

\section{EVOLUCIÓN EPIDEMIOLÓGICA AL CABO DE DOS AÑOS Y MEDIO}

a) Meningococo C. Inmediatamente tras la campaña de vacunación se inició un paréntesis de 1 año en el que no se diagnosticó 
ningún caso en el grupo vacunado (tasa de incidencia cero), mientras que en el grupo no vacunado la epidemia siguió su curva ascendente con un pequeño estacionamiento en los meses de verano, pero con una clara diferencia respecto al grupo vacunado (figura 1 ).

En febrero de 1998 (1 año tras la campaña de vacunación) se diagnosticó el primer caso de meningitis $C$ en una niña vacunada, desde entonces y hasta la semana 40 de 1999 en que se hace este análisis (es decir, en los 2 años y 7 meses que siguen a la campaña de vacunación), sólo se han declarado en Cantabria 4 casos ciertos y 1 dudoso. Se trató de una niña de 12 años ingresada para estudio de fiebre sin foco, en quien se aisló en sangre Meningococo C, Salmonella Typhi y Virus de Ebstein-Barr. A pesar del diagnóstico dudoso, está incluida como infección en vacunados (sobre una población vacunada de 114.598 personas), los 5 con evolución favorable. El año epidemiológico 98-99 finalizó con una tasa de incidencia de enfermedad meningocócica $C$ de 1,29/100.000 en el conjunto de la población, y de 2,78/100.000 en el grupo de riesgo de 18 meses a 19 años. En la figura 2 se muestra la evolución a lo largo de los años epidemiológi$\cos 95-96$ a $98-99$, observándose que en el tercer año tras la vacunación la incidencia en el grupo de riesgo se mantiene disminuida un $80 \%$ y en el conjunto de la población un $77,3 \%$. Insistimos en que en los 12 meses tras la campaña la incidencia en el grupo de riesgo fue cero, lo que no queda reflejado en las gráficas, al no coincidir estos 12 meses con el año epidemiológico ni con el año natural. La tasa primaria de ataque en el grupo de riesgo, en la temporada 98-99 nunca ha superado el $0,87 / 100.000$ (antes de la campaña: 14/100.000). La letalidad ha caído a cero y no ha habido casos secundarios, por lo que no ha sido necesario aplicar pautas de revacunación.

Estos resultados superan los efectos beneficiosos de la vacuna descritos en la bibliografía (porcentajes de protección clínica de 85 $100 \%$ en los niños mayores y adultos, peró sólo del $70 \%$ en los $<5$ años, del $55-75 \%$ entre los 18-24 meses y los 3 años, y poca o nula eficacia en los $<18-24$ meses). Ello lo atribuimos al «efecto barrera» de haber realizado la cam-

Figura 1

Meningococo C en Cantabria (1996-99)

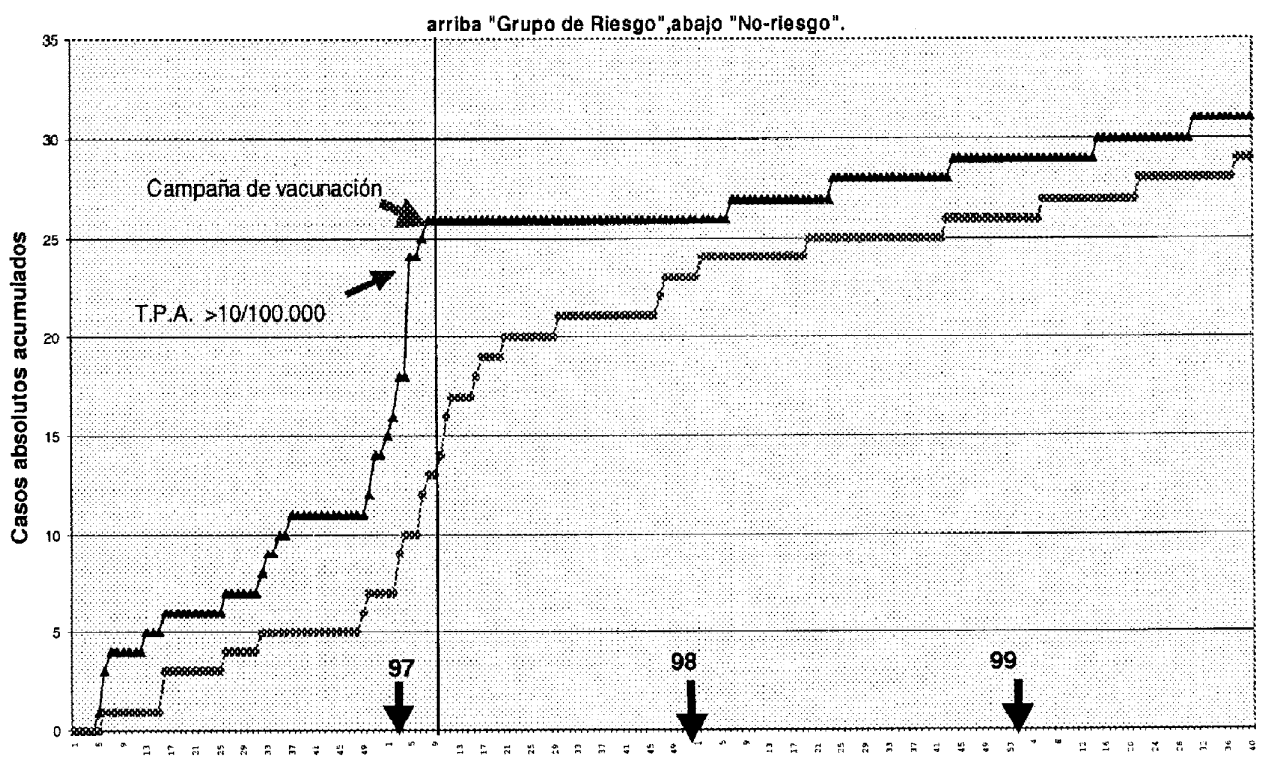


Figura 2

Meningitis C en Cantabria. Incidencia por años epidemiológicos

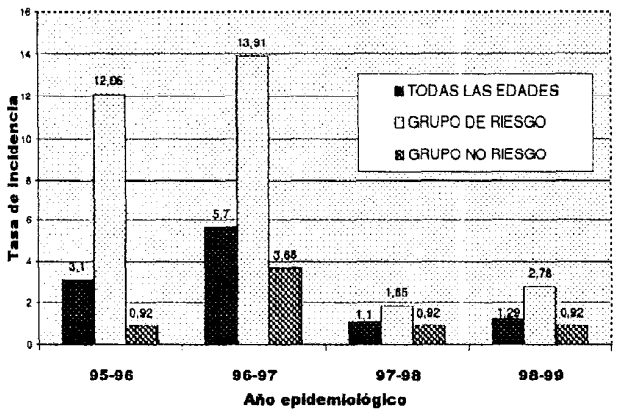

paña de vacunación muy precozmente (3 semanas después de superarse la tasa primaria de ataque de 10/100.000) y muy rápidamente (2 semanas), lo que sin duda hizo disminuir la circulación del meningococo entre la población susceptible, y potenció la efectividad de la vacuna en cada caso individual.

b) Otros serogrupos. Con relación a los otros serogrupos, la incidencia del B se mantuvo sin cambios en los dos años epidemiológicos posteriores a la campaña. Por su parte, los diagnósticos de enfermedad por meningococo «no grupado» han disminuido un $96.77 \%$ (figura 3). Esto último sugiere que la mayoría de los «no grupados» durante el brote epidémico eran en realidad del serogrupo $\mathrm{C}$ (si no, no se explica un descenso tan llamativo en pocos meses tras la campaña), con lo que la eficacia de la campaña de vacunación estaría infraestimada. En efecto, la efectividad vacunal sería aún mayor al ser la tasa de incidencia por meningococo $\mathrm{C}$ antes de la campaña casi el doble de la utilizada en los cálculos.

\section{EL PROBLEMA DE LAS MENINGITIS «BACTERIANAS SIN GERMEN IDENTIFICADO»}

En los meses inmediatos a la campaña de vacunación se produjo un incremento en los casos de meningitis catalogadas como «bacterianas» sin aislamiento de ningún germen en el
Figura 3

Scrogrupos: Evolución por años epidemiológicos

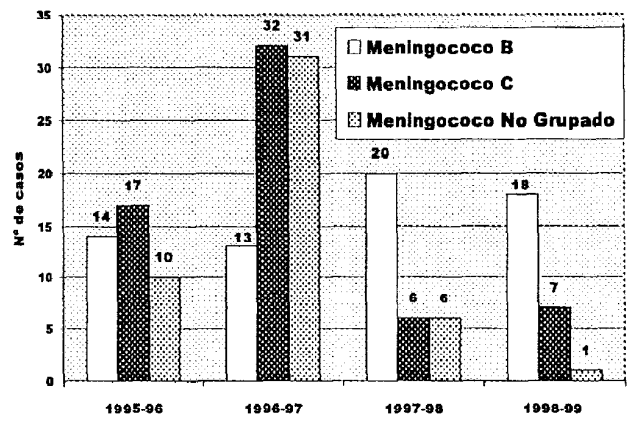

LCR o el hemocultivo, incremento que fue más manifiesto en el grupo vacunado (figura 4). Este incremento coincidió en el tiempo con la máxima preocupación social y médica por la meningitis, y también con los meses iniciales de la campaña de vacunación. En el verano de 1997 (3 meses tras estabilizarse los casos de meningitis $\mathrm{C}$ ) dejaron de declararse casos con este diagnóstico durante casi un año, para volver a aumentar en la primavcra de 1998 simultáneamente con los primeros casos de meningitis $\mathrm{C}$ en vacunados, siguiendo a partir de entonces curvas paralelas.

En la figura 5 se representan los casos de meningitis «bacterianas sin germen» respecto al total de meningitis meningocócicas en el grupo vacunado («de riesgo») y no vacunado (de «noriesgo»), a lo largo de 3 años sucesivos. $\mathrm{Al}$ expresar esta relación en porcentaje se pone de manifiesto la carga proporcional de este diagnóstico respecto al total de meningitis realmente meningocócicas en cada grupo. Una vez más se evidencia que en los meses de 1997 que siguieron a la campaña de vacunación los diagnósticos de meningitis «bacteriana sin germen» fueron especialmente frecuentes en el grupo de riesgo (76,92\% respecto al total de meningocócicas), y mucho menos en el grupo de «no-riesgo» $(45,45 \%)$. Dos años después la carga proporcional de este diagnóstico en cada grupo se igualó, con porcentajes cercanos al $22 \%$.

Este comportamiento atípico de los casos diagnosticados de «meningitis bacteriana sin 
Figura 4

Comparación meningitis $\mathrm{C}$ y bacterianas sin germen

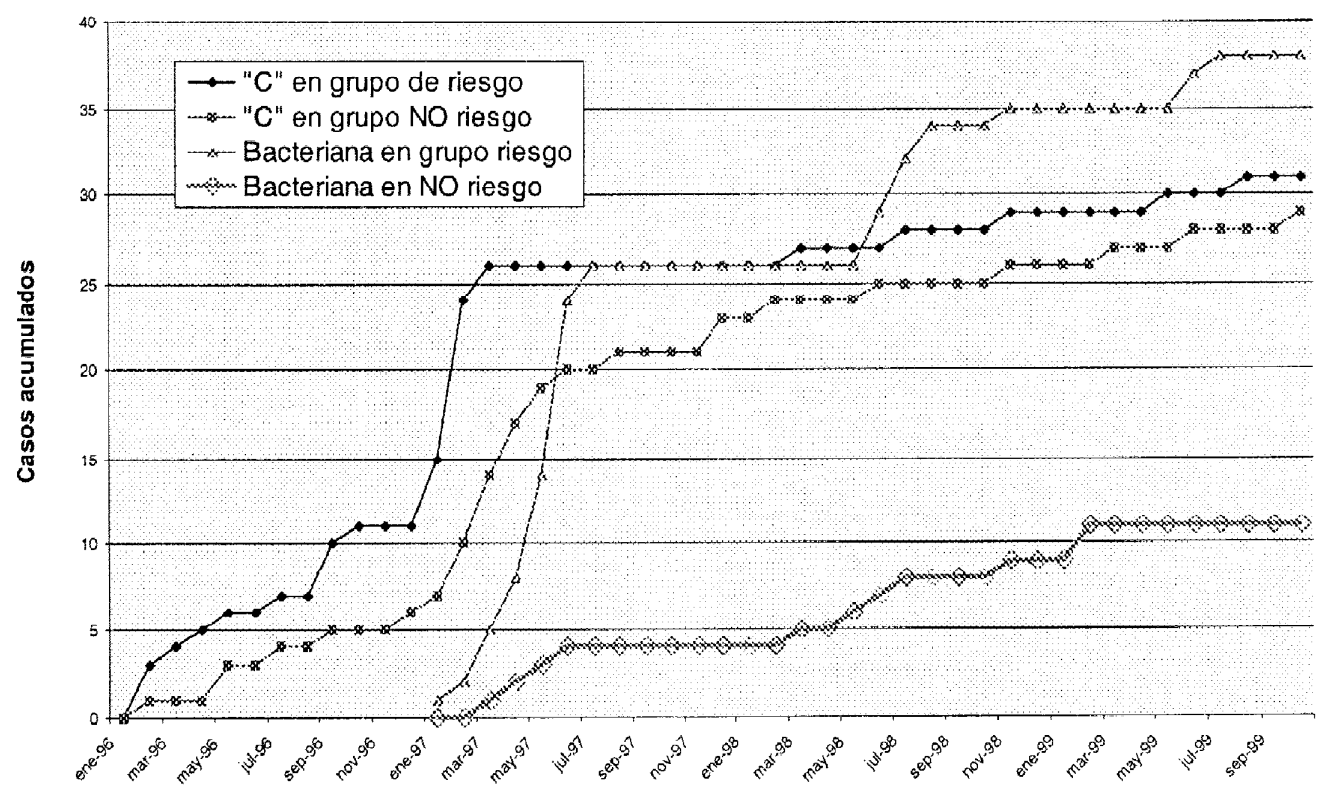

germen identificado» puede explicarse por dos hipótesis:

- Sobrediagnóstico de meningitis bacterianas. Se trataría de un sesgo en el diagnóstico debido a prácticas de medicina defensiva por parte de los profesionales (el $56 \%$ de estos diagnósticos, en 1997, se produjo en las 6 semanas siguientes al fallecimiento de una joven no vacunada), que serían proclives a diagnosticar como bacterianas algunas meningitis que en otras circunstancias hubieran diagnosticado de asépticas. Con esta actitud se disminuirían los posibles riesgos al no dejar de tratar y efectuar quimioprofilaxis en ningún caso. Esta hipótesis se ve apoyada por los análisis de 56 muestras de LCR de meningitis víricas o «bacterianas sin germen» (tabla 1). En esta comparación se evidencia un promedio de 633 leucocitos $/ \mu$ l con un $80 \%$ de polinucleares para las meningitis «bacterianas sin germen» -es decir, inferior a la cifra habitualmente considerada de 1000/ml-, frente a 177 leucocitos $/ \mu 1$ con un $41 \%$ de polinucleares en las víricas. Además, si se excluye del análisis un único caso de «bacteriana sin germen» en el que se hallaron 11.000 leucocitos/ $\mu$ l, las cifras para éste diagnóstico serían en promedio de 218 leucocitos con un $80 \%$ de polinucleares, perfectamente compatible con el cuadro inicial de una meningitis víriça. La agrupación de casos alrededor de la campaña de vacunación también es compatible con esta hipótesis (medicina defensiva en el momento de máxima preocupación social y/o brote de meningitis vírica estacional). El $2^{\circ}$ aumento a principios de 1998 sería explicable por un segundo brote de meningitis vírica, y la diferencia entre vacunados y no vacunados por un sesgo del obser-

Tabla 1

Promedio de celularidad en 56 LCR

\begin{tabular}{|cccc|}
\hline Bacteriana sin germen & \multicolumn{3}{|c|}{ Vírica } \\
\hline $\begin{array}{c}\text { Células } \\
633^{*}\end{array}$ & 80 & Células & $\%$ PN \\
177 & 41 \\
\hline
\end{tabular}

(*) 218 células si se excluye un único caso que presentó 11.000 . 


\section{Figura 5}

\section{Serogrupos: Evolución por años epidemiológicos}

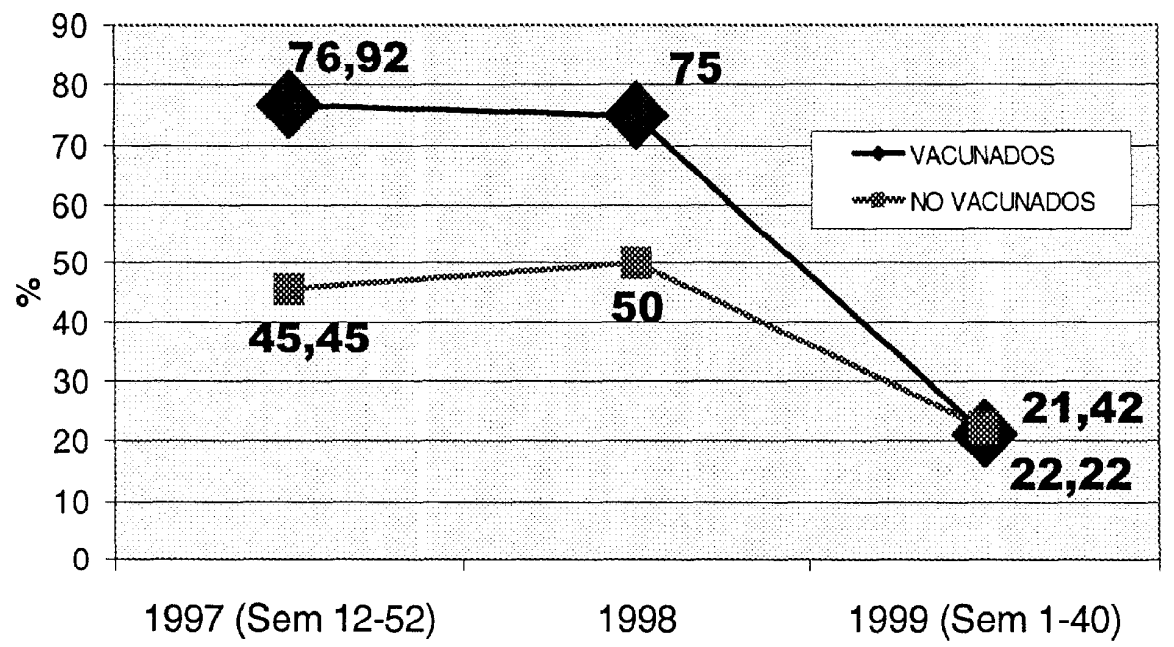

vador, ya que la población de riesgo se atiende en Cantabria en un hospital pediátrico, y la de «no-ricsgo» en uno de adultos, ubicados en edificios diferentes y con diferente personal.

- Subdetección de meningococo $C$ en sujetos vacunados. Según esta hipótesis, la vacunación interferiría con la capacidad de aislamiento en sangre o LCR del meningococo $\mathrm{C}$ y provocaría un cuadro clínico más benigno. Esta hipótesis explicaría los picos del diagnóstico de «bacterianas sin germen» coincidiendo con los picos de meningococo $\mathrm{C}$, y el mayor número de casos con este diagnóstico en vacunados. Sin embargo, no explicaría la tendencia a igualarse la carga proporcional de este diagnóstico en vacunados y no vacunados en el tercer año tras la campaña, pues cualquiera que fuera el mecanismo de esta interferencia debería prolongarse - al menos - durante el tiempo de protección vacunal, que en las edades mayores del grupo de riesgo se cifra entre 5 y 10 años.

Con nuestros datos no podemos decantarnos por ninguna de las dos hipótesis (pues no se realizaron técnicas más específicas, como PCR, para aclarar la etiología de las meningitis «bacterianas $\sin$ germen»), pero dejamos constancia de que aplicando los criterios más conservadores de diagnóstico de meningitis bacterianas (es decir, el umbral de 1.000 leucocitos/ $\mu \mathrm{l}$ en $\mathrm{LCR}$ ) se habrían excluido del diagnóstico de meningitis bacteriana todas las catalogadas de «bacterianas sin germen» menos una.

\section{EFECTIVIDAD VACUNAL}

Clásicamente la efectividad vacunal se calcula con la fórmula:

$\mathrm{EV}=[$ (Tasa en $\mathrm{NO}$ vacunados - tasa en vacunados) / Tasa en NO vacunados] $\times 100$.

Debido a lo reducido del grupo de riesgo que quedó sin vacunar en Cantabria (aproximadamente 2000 niños, muchos de los cuales se habrían vacunado por adquisición de la vacuna en farmacias), no nos es posible calcular la efectividad utilizando la tasa en no vacunados en el mismo periodo de tiempo, al ser cero el denominador. Por ello se ha utilizado la tasa en el grupo de riesgo ( 18 meses a 19 años) en el año anterior a la campaña de vacunación, asumiendo que habría sido la misma en un grupo control que se hubiera quedado sin 
vacunar durante la epidemia. Esta aproximación es la única posible, y siempre dará estimaciones de efectividad vacunal inferiores a la real. En efecto, al escogerse el año inmediato anterior al brote, la tasa en no vacunados será inferior a la que hubieran tenido los no vacunados durante la epidemia.

Por otra parte, ya se comentó que la campaña de vacunación indujo una caída del $96,77 \%$ en los meningococos «no grupados», lo que sugiere que la mayoría de los «no grupados» durante el brote epidémico era en realidad del serogrupo $\mathrm{C}$ (la vacuna va dirigida contra los serogrupos A y $\mathrm{C}$, pero en Cantabria los casos por serogrupo A siempre han sido excepcionales). Si, utilizando este argumento, todos los «no grupados» se computaran como serogrupo $\mathrm{C}$, la incidencia previa a la campaña de vacunación sería casi del doble y con ello la efectividad vacunal sería aún mayor. Debido a estas dos circunstancias, las estimaciones de efectividad dadas a continuación deben considerarse infraestimadas.

Con estos criterios, en la figura 6 puede verse la efectividad vacunal en $\operatorname{los} 2$ años y medio siguientes a la campaña de vacunación, destacando que se mantiene por encima del $91 \%$ en todas las edades. Merece la pena destacar las edades de los casos índice: 5, 2, 12, 9 y 2 años (este último vacunado 2 años tras la campaña). Por lo tanto no se confirma el temor inicial de un rebrote epidémico en las edades inferiores (se dudaba de la efectividad de la vacuna en los menores de 3-4 años, y especialmente en los de 18-24 meses). En la figura 7 se muestra la efectividad vacunal (eficacia «clínica») frente al porcentaje de niños con tasa "protectora» de anticuerpos bactericidas, en el año siguiente a la campaña de vacunación y divididos por grupos de edad ${ }^{1}$. En ella se comprueba que la efectividad vacunal es muy superior a la tasa de «seroprotección» en todas las edades, pero sobre todo en los lactantes y preescolares, hecho que ya se ha citado en otros trabajos ${ }^{2}$ y que se atribuye a la existencia de factores inmunobiológicos protectores, distintos de los anticuerpos y no bien conocidos, y al ya mencionado «efecto barrera» de haber realizado la campaña de vacunación muy precoz y rápidamente, lo que habría disminuido la circulación del meningococo entre la población susceptible.

Figura 6

Comparación meningitis C en Cantabria: Efectividad vacunal

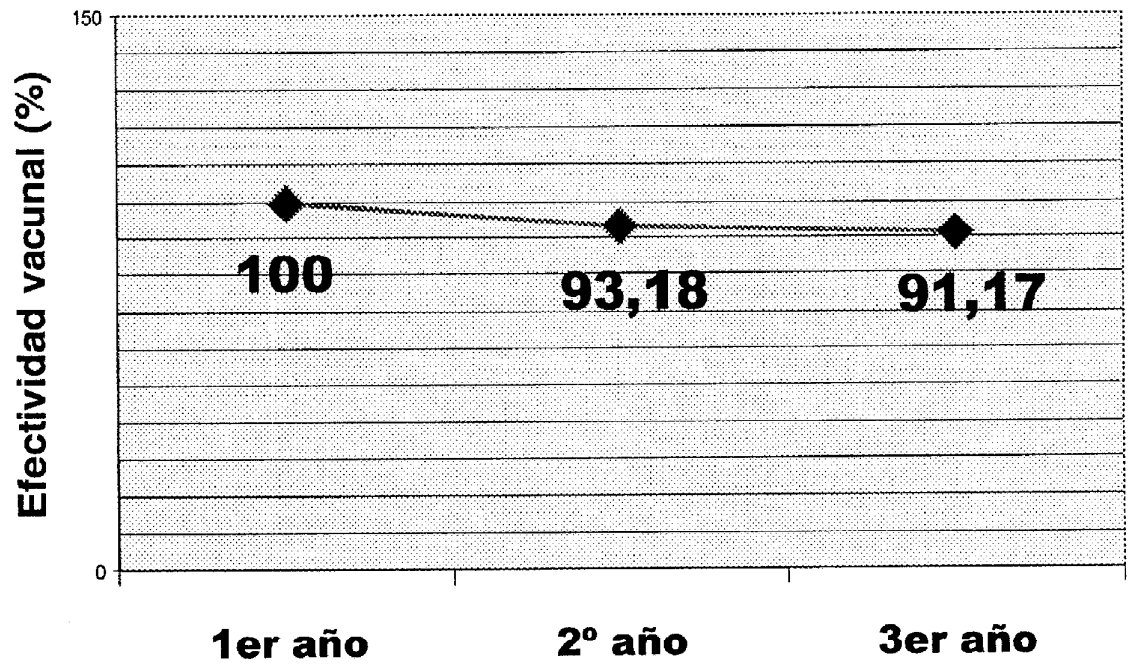

Años tras la campaña 
Figura 7

Efectividad vacunal / Ac. Bactericidas

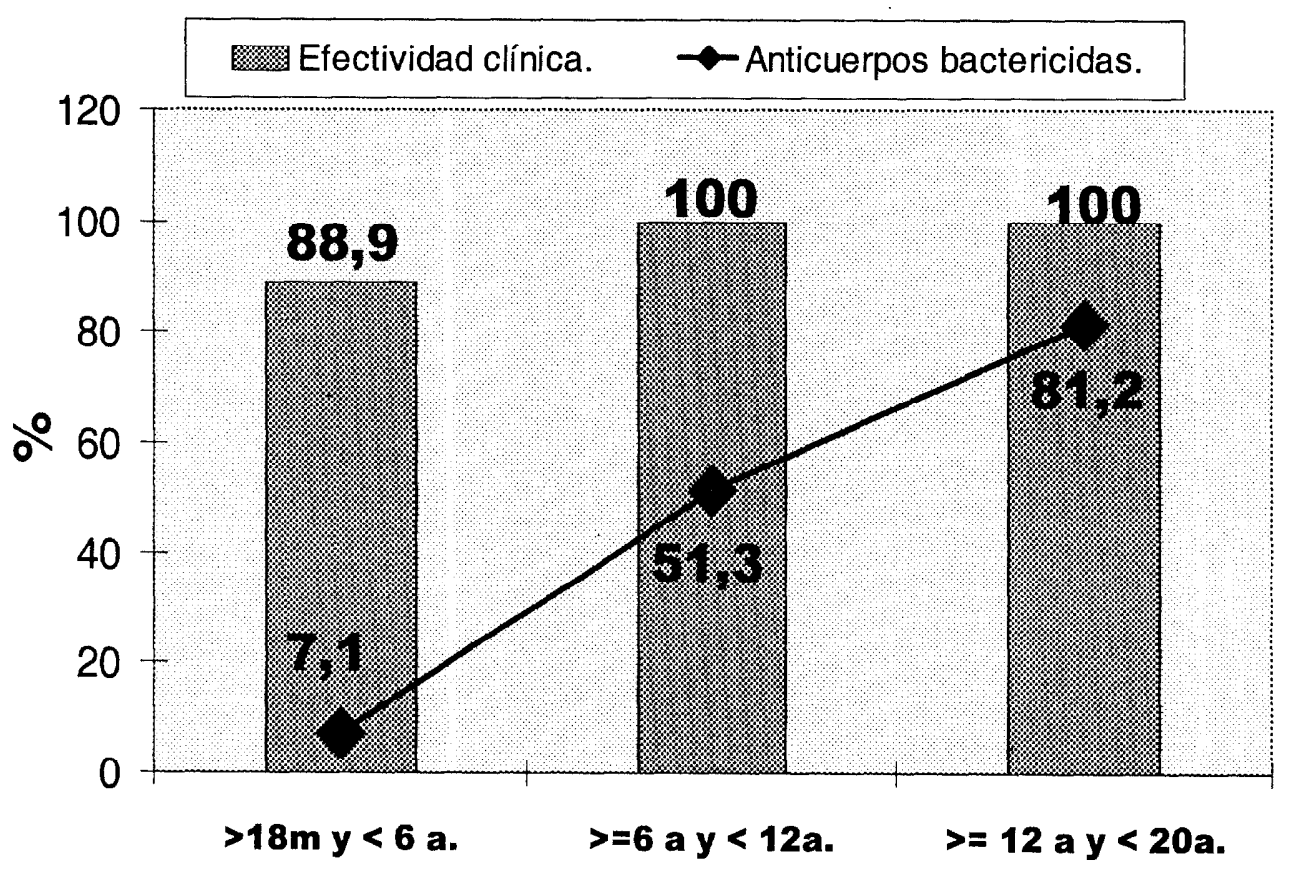

\section{INTERVENCIONES COMUNITARIAS DE QUIMIOPROFILAXIS}

Además de la vacunación, la otra medida de salud pública útil en la enfermedad meningocócica es la quimioprofilaxis en el entorno de los casos. Se entiende por intervención comunitaria de quimioprofilaxis la que rebasa el ámbito familiar y doméstico más cercano, y en la práctica suele tratarse de intervenciones en el ambiente escolar o universitario. Es de destacar el elevado número en 1997 (49 intervenciones afectando a 3.170 personas) coincidiendo con el brote epidémico, y la disminución posterior hasta 14 intervenciones afectando a 650 personas en lo que va de 1999. La mayoría de estas intervenciones se realiza- ron en las primeras $24-48$ horas del diagnóstico. Este exceso de quimioprofilaxis, derivado del exceso de diagnósticos de meningitis «bacteriana», es preocupante en cuanto a la posible aparición de resistencias y/o de yatrogenia.

\section{BIBLIOGRAFÍA}

1. González de Aledo A y García Merino J. Seroprevalencia de anticuerpos bactericidas frente al Meningococo $\mathrm{C}$ en Cantabria 10 meses después de la campaña de vacunación. Rev Esp Salud Pública 1998; 72: 365-74

2. Peltola H. Meningococcal vaccines. Current status and future possibilities. Drugs 1998; 55: 347-66. 


\section{FE DE ERRATAS}

En el artículo Evaluación de la campaña de vacunación en Cantabria dos años de evolución epidemiológica. A González de Aledo y J García Merino. Vol 74 (4): 405 411, deben corregirse los siguientes puntos:

1. El segundo párrafo de la primera columna de la página 406 , debe quedar como sigue:

En febrero de 1998 (1 año tras la campaña de vacunación) se diagnosticó el primer caso de meningitis $C$ en una niña vacunada, desde entonces y hasta la semana 40 de 1999 en que se hace este análisis (es decir, en los 2 años y 7 meses que siguen a la campaña de vacunación), sólo se han declarado en Cantabria 4 casos ciertos y 1 dudoso en niños vacunados (sobre una población vacunada de 114.598 personas), los 5 con evolución favorable. El caso dudoso era una niña de 12 años ingresada para estudio de fiebre sin foco, en quien se aisló en sangre Meningococo C, Salmonella Typhi y Virus de Ebstein-Barr, la cual, a pesar del diagnóstico dudoso, está incluida como infección meningocócica en todos los cálculos. El año epidemiológico 98-99 finalizó con una tasa de incidencia de enfermedad meningocócica $C$ de 1,29/100.000 en el conjunto de la población, y de 2,78/100.000 en el grupo de riesgo de 18 meses a 19 años.
En la figura 2 se muestra la evolución a lo largo de los años epidemiológicos 95-96 a 98-99, observándose que en el tercer año tras la vacunación la incidencia en el grupo de riesgo se mantiene disminuida un $80 \%$ y en el conjunto de la población un $77,3 \%$. Insistimos en que en los 12 meses tras la campaña la incidencia en el grupo de riesgo fue cero, lo que no queda reflejado en las figuras, al no coincidir estos 12 meses con el año epidemiológico ni con el año natural. La tasa primaria de ataque en el grupo de riesgo, en la temporada 98-99 nunca ha superado el $0,87 / 100.000$ (antes de la campaña: 14/100.000). La letalidad ha caído a cero y no ha habido casos secundarios, por lo que no ha sido necesario aplicar pautas de revacunación.

2. En la primera columna de la página 408, el recuento de células en líquido cefalorraquídeo (LCR) está en mililitros y debe ser en microlitros: $1000 /$ microlitro.

3. El título de la figura 5 debe decir: Porcentaje de meningitis bacterianas sin germen respecto al total de meningitis meningocócicas.

4. El título de la figura 6 debe decir: Meningitis $\mathrm{C}$ en Cantabria: efectividad vacunal. 